\title{
IN THE MUSEUM
}

\section{A J Ryan (University of Natal)}

The Museum of Classical Archaeology has on loan from Dr. David Spurrett four arrowheads of varying antiquity, ranging from the late Neolithic to the Hellenistic period. Although small, these artefacts are of significant pedagogical value to a museum whose primary function is teaching. In particular, the Classics Programme at the University of Natal allows senior students, in lieu of a research essay, to submit web projects based on the artefacts in the museum. ${ }^{1}$ Ancient weaponry and warfare has always been a popular topic for students and these items offer considerable scope for new projects.

The oldest of the artefacts is a light toffee-coloured lanceolate Neolithic flint arrowhead from England dating to around 3500 BC (L.2003.X: Pl.1a). It measures $13.1 \mathrm{~mm}$ at its widest point, is $38.1 \mathrm{~mm}$ long and $3.8 \mathrm{~mm}$ deep. The convex basal edge is slightly thinned to facilitate hafting to the shaft. In the absence of expertise in metalwork, flint was the most useful material from which tools could be fashioned, owing to the fact that, unlike most other rocks, flint flakes smoothly when struck and a craftsman is able to shape the stone with a high degree of precision. Although the primary subsistence strategy at the time our implement was manufactured was farming, which had started to replace hunter-gathering around $4500 \mathrm{BC}$, people still engaged in hunting. It is likely that this arrowhead was used for this purpose, but we cannot rule out the possibility that it was used in combat since there is ample evidence for warfare in the Neolithic ${ }^{2}$, and as early as the Palaeolithic, there is evidence that arrows were used against humans. ${ }^{3}$

The advent of metalwork precipitates the beginning of the Bronze Age and the end of the Neolithic. A single starting date for the Bronze Age cannot be stated with any authority since different parts of Europe began using Bronze at different times. In addition, how one dates the start of the Bronze Age is to some extent contingent upon the criteria based upon which one defines the term "Bronze Age". Although copper was used in the south-east of Europe from as early as $4500 \mathrm{BC}$, only by around $2600 \mathrm{BC}$ was the deliberate ${ }^{5}$ alloy, bronze, in widespread use throughout the Aegean, and hence many scholars consider $2600 \mathrm{BC}$ to be the start of the Bronze Age in Greece. Bronze, which is composed of copper mixed with 10-20\% tin, has several advantages over copper, not least of which are that it is harder and that the addition of tin lowers the melting temperature by up to $180^{\circ} \mathrm{C}$. A bronze arrowhead from Asia-minor (L.1998.U: Pl.1b) is most likely an example of late Bronze Age technology although it may be from early in the Iron Age. ${ }^{6}$ As with the flint artefact, the base is designed to facilitate hafting, this time in the form of a prominent tang that would have been inserted

1. The projects are available to view at http://www.classics.und.ac.za/projects.

2. The discovery of fortified cities and combat weapons attests to inter-group conflict in the Late Neolithic (Milisauskas 1978:203).

3. For example, a point, assumed to be an arrowhead, was found embedded in the pelvis of a Palaeolithic skeleton (Bachechi et al 1997).

4. For example, scholars who consider the Bronze Age to begin when bronze supplants stone as the dominant material tend to suggest earlier dates than those who consider it to begin merely when bronze becomes widely used.

5. Certain alloys are naturally occurring, for example trace metals occur in the impurities of the cupriferous ores.

6. The end of the Bronze Age and the beginning of the Iron Age is usually assumed be the late second millennium BC (around 1250). 
into a hole in the shaft of the arrow. Arrows from this period frequently use this method of hafting and some examples have ridges in the tang to aid in securing the point. ${ }^{7}$ The object is $11.1 \mathrm{~mm}$ at its widest point and $77.8 \mathrm{~mm}$ long. The blade is flat and was probably cast with an open mould and then hammered flat. The open mould is suited to flat mass-produced artefacts, as it is easy to re-use. The arrowhead is quite similar to many others found in the Aegean during the Bronze Age ${ }^{8}$ many of which were found in warrior's tombs. It is likely that this particular artefact was intended for combat, but we cannot rule out the possibility that it was used for hunting.

The Asians, particularly the Scythians, were later renowned for their skill in archery, and their exploitation of this skill in combat. Peisistratos was sufficiently impressed that he used Scythian archers as his bodyguard - a situation reflected in numerous Attic vase-paintings from the second half of the sixth century, ${ }^{9}$ showing Scythian archers in their Asiatic dress, accompanied by the composite bow and gorytos. ${ }^{10}$ By contrast, while it is certain that the Greeks did employ archers in warfare, the evidence for their large scale use in battle after the Bronze Age is limited, except in Crete. A dearth of both arrowhead finds from the dark ages and references to archers in epic poetry suggests that archery was not practiced in any systematic way during this period, ${ }^{11}$ but by $700 \mathrm{BC}$ archers have appeared on vase-paintings and numerous arrowheads found around the Aegean confirm their use. ${ }^{12}$ However, there is little evidence to suggest that they were used as anything more than auxiliary forces during the Archaic and Classical periods. Possible reasons for the Greeks not making large-scale use of archers in warfare is that they had witnessed the ineffectiveness of Persian arrows against themselves at Marathon, and that the limited range of the arrow ${ }^{13}$ did not allow for sustained fire over a long period against a charging enemy. ${ }^{14}$ It is only during the Hellenistic periods that Greeks began to use the arrow as an important aspect of their battle strategy.

The final two pieces presented here are Greek bronze arrowheads found in Asia Minor, dateable to the second century BC. The first of these (L.2000.V: P1.2a) is socketed with a leaf-shaped blade. It measures $33.1 \mathrm{~mm}$ in length and $11.1 \mathrm{~mm}$ in width. The long socket, which has a small hole near the base, is met halfway down the blade by a mid-rib which terminates at the distal end of the point. This general design is the most common found at the site of the siege of Smyrna and appears in mainland Greece from the archaic period onwards. $^{15}$ The second of the Greek pieces (L.2003.Y: P1.2b), although contemporary with the first, is of a later design that was probably introduced to Greece during the Persian wars. ${ }^{16}$ It is three-sided and pyramidal in shape, measuring $15.8 \mathrm{~mm}$ in length and $6.6 \mathrm{~mm}$ in width. It is barbed and socketed, with holes in each of two of the three sides. Unlike the two older

7. An example of which are the arrowheads found in Ayios Ionnis (Hood 1956:96).

8. For example, Branigan 1974:164 nos 507-512.

9. Snodgrass 1999:83.

10. A combination of bow case and quiver.

11. Snodgrass (1999:40) points out that the scarcity of arrowhead finds may also be due, at least in part, to a cessation of the practice of burying arrowheads: the source of most our finds from this period.

12. For example, at the siege of Smyrna, arrowheads were clearly used by both the Lydians and the Ionians (Nichols 1958-9). Nichols points out, however, that the large variety of arrowhead designs suggests there may have been mercenaries from Crete and elsewhere employed by both sides.

13. MacLoed (1969 and 1972) provides an illuminating discussion of the ancient evidence on the range of the bow, suggesting 160-175 metres as a probable effective range.

14. $O C D^{3}$ s.v. archers (Greek and Hellenistic).

15. Snodgrass 1964:151.

16. Snodgrass 1964:151. 
pieces in the collection, which were designed to be hafted by inserting the bases into holes in the shafts, the two Greek points have sockets at the base into which the shaft would have been inserted. Both these pieces are considerably more elaborate in shape than the first two, and were probably cast in a closed mould. The small size of the arrows, by comparison with Bronze Age models, betrays the Greek debt to the expert Scythians in matters ballistic - the Scythians used very thin shafts to allow more arrows to fit into the gorytos.

The four arrowheads presented here are only a small thread in the fabric of European history, but a thread that spans over three millennia. Artefacts that can narrate such stories form a substantial part of the collection of the Museum of Classical Archaeology, and the museum continues to acquire similar pieces for use in teaching, our raison d'être. In this regard, the Museum is grateful to Dr. Spurrett for the loan of these artefacts, and always welcomes such contributions from the public.

\section{BIBLIOGRAPHY}

Branigan, K 1974. Aegean metalwork of the Early and Middle Bronze Age. Oxford: Clarendon.

Bachechi, L, Fabbri, P-F \& Mallegni, F 1997. An arrow-caused lesion in a Late Upper Palaeolithic human pelvis. Current Anthropology 38: 135-44.

Hood, J 1956. Another warrior-grave at Ayios Ionnis near Knossos. BSA 51:81-99.

Hornblower, S \& Spawforth, A (eds) 1996. The Oxford Classical dictionary. Oxford \& New York: Oxford University Press.

McLeod, W 1965. The range of the ancient bow. Phoenix 19:1-14.

McLeod, W 1972. The range of the ancient bow: addenda. Phoenix 26: 78-82.

Milisauskas, S 1978. European prehistory. New York: Academic Press.

Nichols, R V 1958-9. Old Smyrna: The Iron Age fortifications, etc. BSA 53-54: 35-137.

Snodgrass, A M 1999. Arms and armour of the Greeks. Baltimore and London: Johns Hopkins University Press.

Snodgrass, A M 1964. Early Greek armour and weapons. Edinburgh: University Press. 


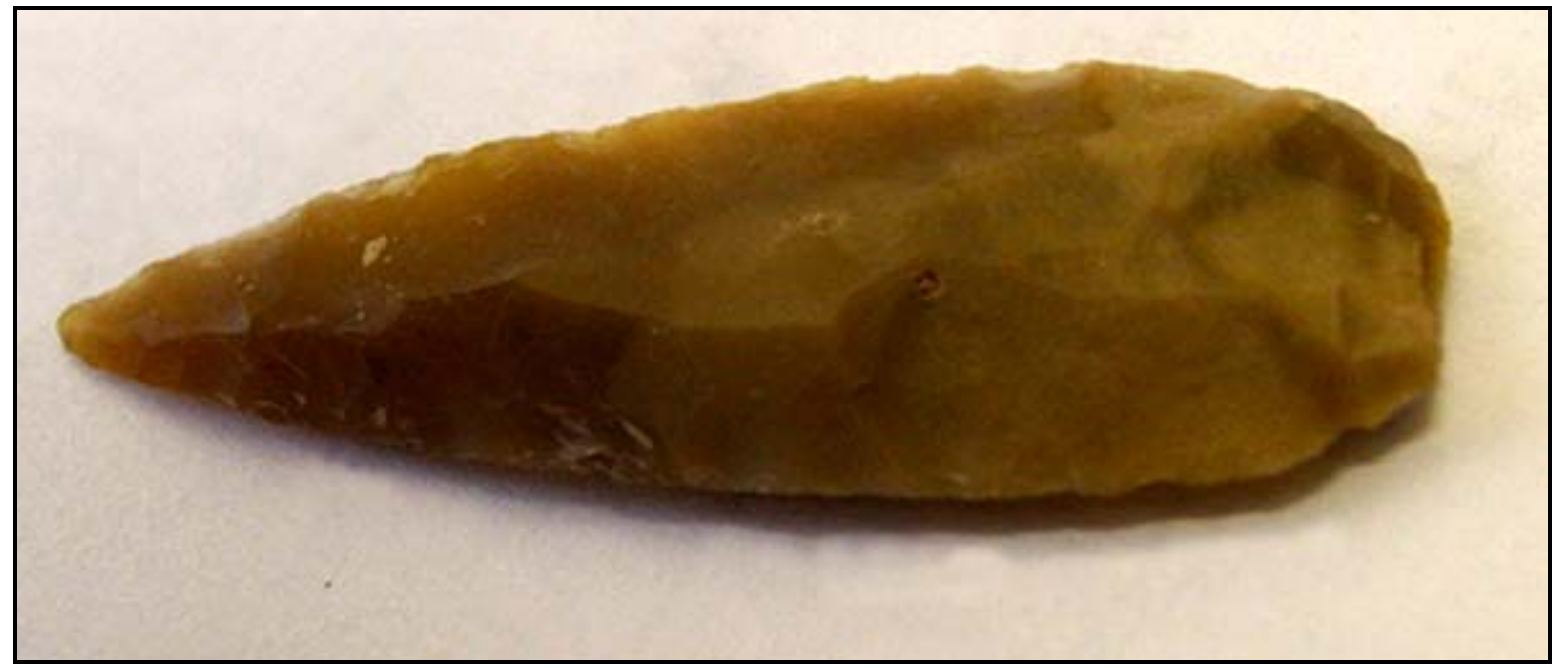

a. Durban L.2003.X

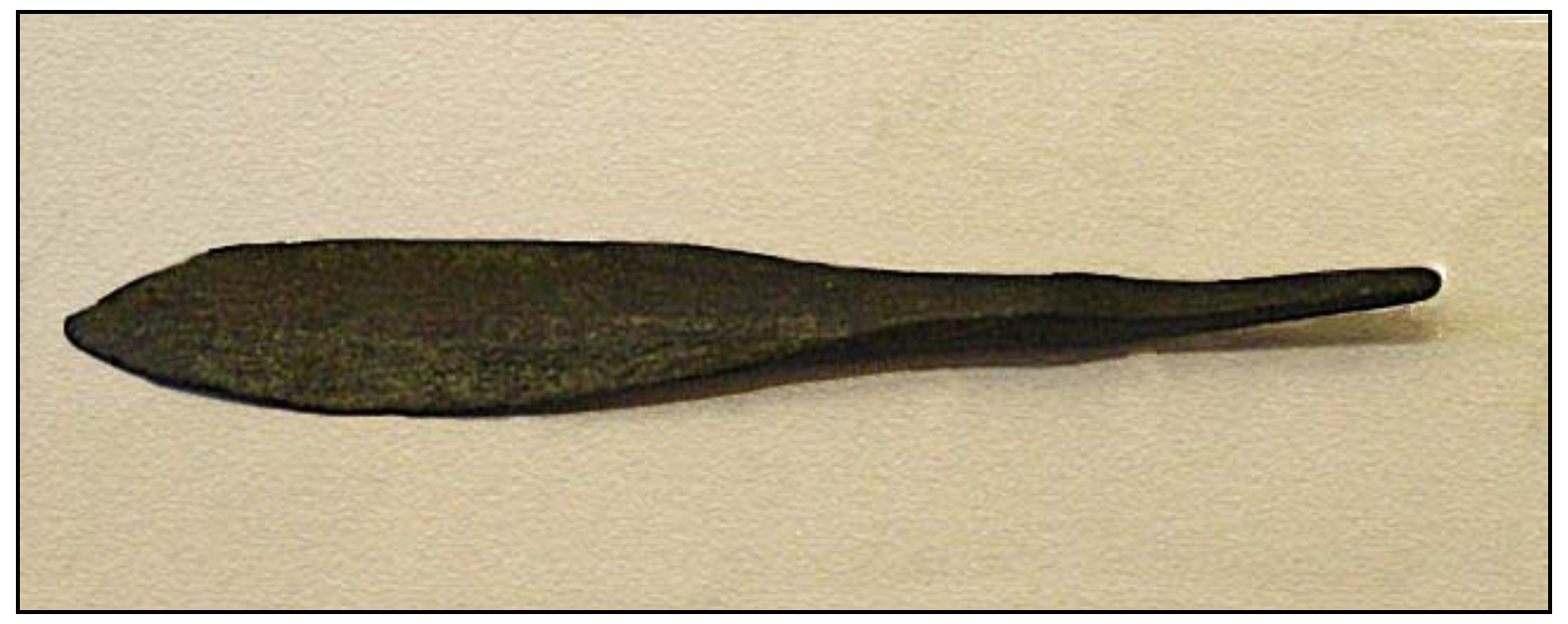

b. Durban L.1998.U

Plate 1 


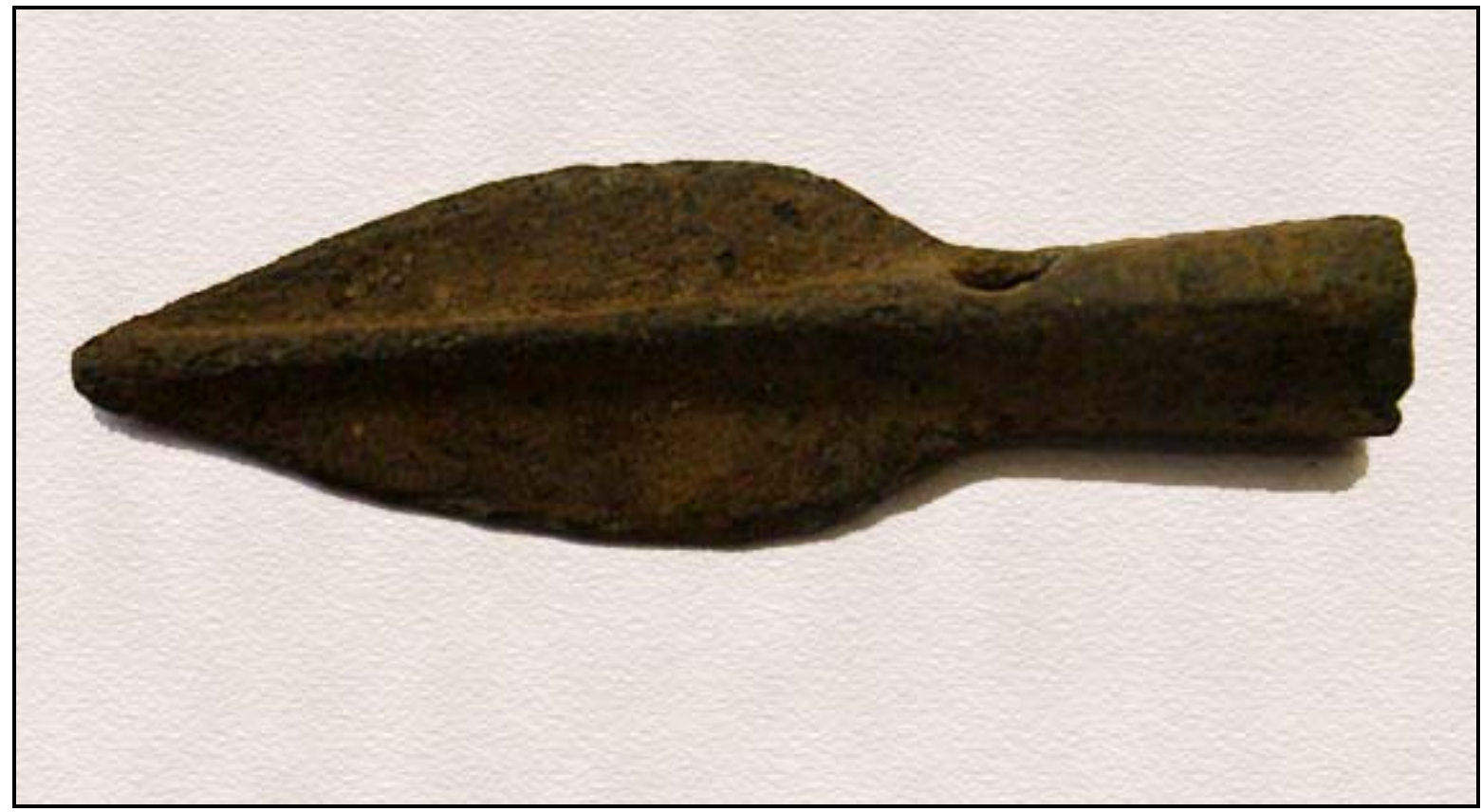

a. Durban L.2000.V

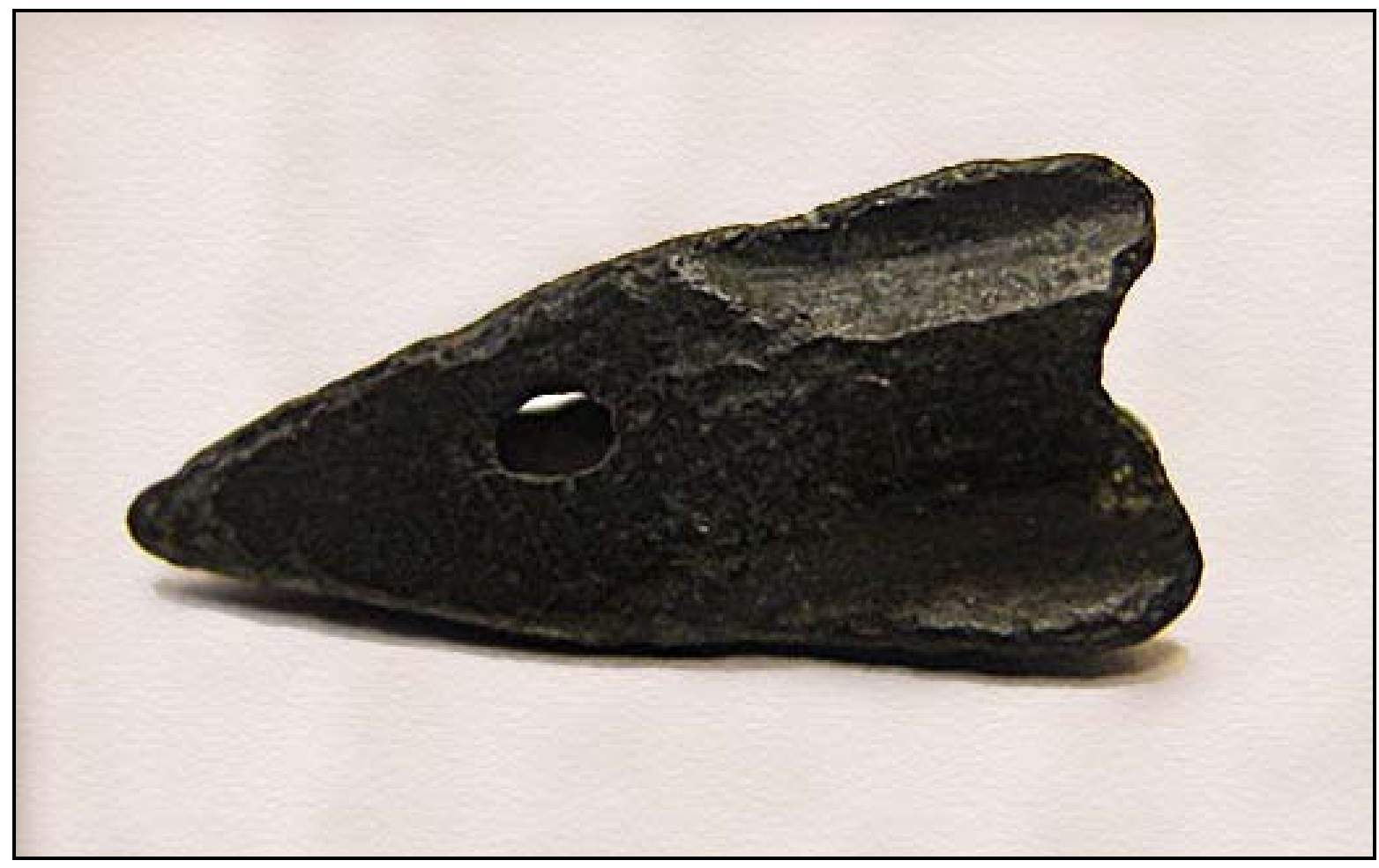

b. Durban L.2003.Y

Plate 2 